\title{
Mesenchymal stem cells activate Notch signaling to induce regulatory dendritic cells in LPS-induced acute lung injury
}

Zhonghua Lu, Shanshan Meng, Wei Chang, Shanwen Fan, Jianfeng Xie, Fengmei Guo, Yi Yang, Haibo Qiu and Ling Liu*

\begin{abstract}
Background: Mesenchymal stem cells (MSCS) have been shown to alleviate acute lung injury (ALI) and induce the production of regulatory dendritic cells (DCregs), but the potential link between these two cell types remains unclear. The goal of this study was to investigate the effect and mechanism of MSC-induced regulatory dendritic cells in ALI mice.

Material/methods: In vivo experiments, C57BL/6 wild-type male mice were sacrificed at different times after intratracheal injection of LPS to observe changes in lung DC maturation and pathological damage. MSCs, DCregs or/ and carboxyfluorescein diacetate succinimidyl ester (CFSE)-labeled DCs were administered to the mice by tail vein, and flow cytometry was performed to measure the phenotype of lung DCs and T cells. Lung injury was estimated by the lung wet weight/body weight ratio and histopathological analysis. In vitro, Western blotting or flow cytometry was used to detect the expression of Notch ligand or receptor in MSCs or DCs after coculture or LPS stimulation. Finally, in vivo and in vitro, we used the Notch signaling inhibitor DAPT to verify the effect of the Notch pathway on MSC-induced DCregs and their pulmonary protection.

Results: We showed significant accumulation and maturation of lung DCs $2 \mathrm{~h}$ after intratracheal injection of LPS, which were positively correlated with the lung pathological injury score. MSC treatment alleviated ALI lung injury, accompanied by a decrease in the number and maturity of classical DCs in the lungs. CFSE-labeled DCs migrated to the lungs of ALI mice more than those of the normal group, and the elimination of CFSE-labeled DCs in the blood was slower. MSCs inhibited the migration of CFSE-labeled DCs to the lung and promoted their elimination in the blood. DCregs, which are obtained by contact coculture of mDCs with MSCs, expressed reduced levels of MHCII, CD86, CD40 and increased levels of PD-L1, and had a reduced ability to stimulate lymphocyte proliferation and activation (expression of CD44 and CD69). mDCs expressing Notch2 significantly increased after coculture with MSCs or rhJagged1, and MSCs expressed more Jagged1 after LPS stimulation. After stimulation of mDCs with recombinant Jagged1, DCs with low expression of MHCII, CD86 and CD40 were also induced, and the effects of both rhJagged 1 and MSCs on DCs were blocked by the Notch inhibitor DAPT. Intra-airway DAPT reversed the inhibitory effect of mesenchymal stem cells on DC recruitment to the lungs and its maturation.
\end{abstract}

Conclusions: Our results suggested that the recruitment and maturation of lung DCs is an important process in early ALI, MSCs attenuate LPS-induced ALI by inducing the production of DCregs by activating Notch signaling.

*Correspondence: liulingdoctor@126.com

Department of Critical Care Medicine, Zhongda Hospital, School

of Medicine, Southeast University, 87 Dingjia Bridge, Hunan Road, Gu Lou

District, Nanjing 210009, China

(c) The Author(s) 2020. This article is licensed under a Creative Commons Attribution 4.0 International License, which permits use, sharing, adaptation, distribution and reproduction in any medium or format, as long as you give appropriate credit to the original author(s) and the source, provide a link to the Creative Commons licence, and indicate if changes were made. The images or other third party material in this article are included in the article's Creative Commons licence, unless indicated otherwise in a credit line to the material. If material is not included in the article's Creative Commons licence and your intended use is not permitted by statutory regulation or exceeds the permitted use, you will need to obtain permission directly from the copyright holder. To view a copy of this licence, visit http://creativeco mmons.org/licenses/by/4.0/. The Creative Commons Public Domain Dedication waiver (http://creativecommons.org/publicdomain/ zero/1.0/) applies to the data made available in this article, unless otherwise stated in a credit line to the data. 
Keywords: Acute respiratory distress syndrome (ARDS), Acute lung injury (ALI), Dendritic cells, Notch, Mesenchymal stem cell (MSC)

\section{Background}

Acute respiratory distress syndrome (ARDS) is a common and clinically complex acute pulmonary inflammatory syndrome with a mortality rate of up to $40 \%$ [1]. Although after decades of exploration, there is still no special treatment for ARDS, treatment options are still confined to supportive care such as the protective mechanical ventilation and prone position ventilation and liquid conservative strategy [2]. Immune cell-mediated aberrant inflammatory responses play a significant role in the development of ARDS [3, 4], but glucocorticoid, surfactants, and other anti-inflammatory drugs, have been failed to show benefits [5]. In order to alleviate aberrant inflammatory of ARDS and ameliorate lung injury, it is urgent to explore additional therapeutic measures.

Mesenchymal stem cells (MSCS), with their pluripotent and immunomodulatory functions, are expected to be a novel therapy for ARDS. Our previous studies showed that MSC can repair alveolar epithelial cells and vascular endothelial cells to ameliorate lung injury in ARDS $[6,7]$. MSCs also possess immunomodulatory properties to immune cells, such as T, B, NK cells, macrophages, neutrophils and dendritic cells (DCs) [8-11]. DCs are the most important specialized antigen presenting cells and play an important role in the regulation of lung immune response network. Previous studies have shown that the maturity of classical dendritic cells ( $\mathrm{cDCs}$ ) in the lungs of ALI mice increased significantly, while inhibition of DCs maturation reduced the inflammatory response and pathological damage in the lungs $[12,13]$. MSC induced mature DCs (mDCs) differentiation into regulatory DC (DCreg) with low expression of CD80 and CD86 DCreg, which induced the expression of CD4, CD25, and Foxp3 in primary splenocytes isolated from mice [14]. MSC also abrogated the capacity of $\mathrm{mDC}$ migration to CCL19, or for DC to display MHC class II peptide complexes recognized by specific antibody, or ovalbumin-pulsed DC to support antigen-specific $\mathrm{CD} 4^{+} \mathrm{T}$ cell proliferation [15]. Therefore, transplantation of MSC to regulate the function of mature DC may bring new light for ARDS treatment, but the regulatory mechanism remains to be elucidated.

Many studies suggest that the immunosuppressive effect of MSCs occurs through paracrine or cell-to-cell contact mechanisms [16-18]. Cell-cell interactions have been demonstrated in the treatment of hematopoietic system-related diseases $[16,18]$. The interaction between the Notch receptor and Notch ligand plays a key role in dendritic cell differentiation or MSC protection against inflammation [19, 20]. Cahill et al. [19] reported that MSCs prevented DC antigen presentation, and knocking down Jagged-1 in MSCs partially reversed this effect. The cell-binding Notch ligand activates notch-1 and notch-2 receptors, leading to accumulation of immature DCs [21]. Whether the Notch pathway is an important link in MSC-induced DCreg generation to alleviate acute lung injury remains unclear.

In the present study, we assessed changes in the lung $\mathrm{cDC}$ phenotype and their association with lung pathological injury in ALI mice, evaluated the effect of MSC transplantation on the lung cDC phenotype in ALI mice and the cellular mechanisms between them, and demonstrated that MSCs induce a shift in $\mathrm{cDCs}$ from a proinflammatory mature type to a tolerant DC to alleviate lung injury.

The aim of this study was to investigate whether the protective effect of MSCs on LPS-induced ALI was achieved by intercellular contact to induce mDCs to differentiate into DCregs and whether the mechanism was related to activation of the Notch pathway. We used coculture experiments to test the phenotype of dendritic cells, the stimulation of $\mathrm{T}$ cell proliferation, and the expression of PD-L1. To explore the mechanism of MSC-induced $\mathrm{mDC}$ conversion to DCregs to alleviate LPS-induced ALI, we used the Notch pathway inhibitor DAPT (a gamma secretase inhibitor) in vivo and in vitro and evaluated lung pathological injury, DC phenotype and function, and pulmonary edema. This study provides an immunological explanation for mesenchymal stem cell reduction of LPS-induced lung injury.

\section{Materials and methods \\ Animals}

Male wild-type 6- to 8-week-old BALB/c and C57BL/6 specific pathogen free (SPF) mice (Laboratory Animal Center of Yangzhou University, Yangzhou, China) were maintained under specific pathogen-free conditions. A SPF animal room and super-clean bench in the laboratory were used for animal feed and experimental manipulation respectively during the whole experiment. The Animal Care and Use Committee of Southeast University approved all of the experimental procedures (Ethics Committee Approval Number: 20170105007). 


\section{MSC culture}

Mouse mesenchymal stem cells and dendritic cells were used in the present study. MSCs derived from the bone marrow of C57BL/6 mice were purchased from Cyagen Biosciences Inc. (Guangzhou, China). The supplier identified MSCs based on the cell surface phenotype and pluripotency. MSCs were cultured in DMEM/F12 containing $10 \%$ fetal bovine serum (Wisent, Nanjing, China) and grown in a humidified $5 \% \mathrm{CO}_{2}$ sterile incubator at $37^{\circ} \mathrm{C}$.

\section{Bone marrow isolation and dendritic cell culture}

Bone marrow (BM)-derived DCs were generated as previously described with minor modifications [22, 23]. BM cells were extracted from the medullary cavity of the femur and tibia in super-clean bench. The erythrocytes were lysed using lysing buffer (BD Pharm Lyse ${ }^{\mathrm{TM}}$, USA), washed three times in phosphate-buffered saline (PBS) and cultured in $100 \mathrm{~mm}$ dishes with $2 \times 10^{6}$ cells in fresh RPMI 1640 (Wisent, Nanjing, China), containing 10\% FBS (Wisent, Nanjing, China), $40 \mathrm{ng} / \mathrm{mL}$ recombinant murine granulocyte-macrophage colonystimulating factor (GM-CSF; NOVUS), and $40 \mathrm{ng} / \mathrm{mL}$ recombinant murine interleukin-4 (IL-4; NOVUS) in a humidified $5 \% \mathrm{CO}_{2}$ sterile incubator at $37{ }^{\circ} \mathrm{C}$. For the isolation of immature DCs (imDCs), non-adherent cells were gently washed away on day 3 , half of the culture supernatant was collected and centrifuged, and the cell pellet was resuspended in $5 \mathrm{~mL}$ fresh medium as described above and returned to the original plate at day 5 . The remaining loosely adherent cell clusters were collected and purified by anti-CD11c micromagnetic beads (Miltenyi Biotec) on day 6. Purified imDCs were cultured for an additional $24 \mathrm{~h}$ under stimulation with $50 \mathrm{ng} / \mathrm{mL}$ bacterial lipopolysaccharide (LPS; SigmaAldrich) and were used as mDCs. The purity of CD11 $\mathrm{c}^{+}$ cells was greater than 90\% (monoclonal antibodies against CD11c, Miltenyi Biotech, Bergisch Gladbach, Germany). Cytofluorimetric analysis was performed to evaluate the DC maturation phenotype (monoclonal antibodies against CD40, CD86, and MHC-II, Miltenyi Biotech, Bergisch Gladbach, Germany).

\section{DC and MSC coculture}

$\mathrm{mDCs}\left(5 \times 10^{5}\right.$ cells/well $)$ were seeded into 6-well plates $4 \mathrm{~h}$ after MSCs $\left(5 \times 10^{6}\right.$ cells/well $)$ in RPMI 1640 containing $5 \%$ fetal bovine serum (FBS); in the presence or absence of DAPT $(5 \mu \mathrm{M})$ at $37{ }^{\circ} \mathrm{C}$ in $5 \% \mathrm{CO}_{2}$. After coculture for $72 \mathrm{~h}$, the suspended dendritic cells were collected for examination or applied to subsequent experiments.

\section{ALI model}

In SPF animal room, the ALI model was induced as previously described with minor modifications [7]. Briefly, mice were intraperitoneally injected with $50 \mathrm{mg} / \mathrm{kg}$ pentobarbital. LPS (5 mg/kg) (Sigma-Aldrich) was delivered to the lungs by transtracheal injection, and the incision was sewn up. The mice were returned to the cage until they were fully awake.

\section{Reagent treatments}

Previous studies have found that $\gamma$-secretase inhibitors impair MSC-induced DCreg production by inhibiting the Notch pathway $[18,19]$. To determine the inhibitory effect of DAPT on the production of MSC-induced tolerant DCs within 3 days, MSC + DC + DAPT group: DAPT (Absin, China) was added to MSC-DC or recombinant Jagged 1 cultures at $1 \mathrm{mM}$ on day 0 . When the culture medium was changed, DAPT was added to the fresh medium at the same concentrations. Because DAPT was diluted in DMSO, the control MSC-DCs, Jagged1-DCs, mDC were cultured with DMSO. GMCSF was added to the medium in each group to maintain the final concentration of $20 \mathrm{ng} / \mathrm{mL}$.

\section{Experimental groups and sample acquisition}

To investigate the changes in lung DCs and pathological damage at different times after ALI modeling, the mice were randomly assigned to one of the following seven groups ( $\mathrm{n}=6$ mice per group): $24 \mathrm{~h}, 12 \mathrm{~h}, 6 \mathrm{~h}$, $4 \mathrm{~h}, 2 \mathrm{~h}, 1 \mathrm{~h}$ and $0 \mathrm{~h}$. Mice in the 24, 12, 6, 4, 2, 1 and $0 \mathrm{~h}$ (control) groups were sacrificed after an intratracheal injection of $5 \mathrm{mg} / \mathrm{kg}$ lipopolysaccharide (LPS) (Additional file 1: Fig. S1A). Lung tissue was collected for single cell isolation and histological examination in accordance with slightly modified methods [12].

After confirming the lung DC maturation time in ALI mice, MSCs were administered to the mice at $4 \mathrm{~h}$ after LPS, and their effects on lung $\mathrm{mDCs}$ and lung pathological damage were observed. The mice were randomly assigned to one of the following three groups ( $\mathrm{n}=6$ mice per group): MSC + ALI group (MSC) mice received MSCs (500,000 cells in $150 \mu \mathrm{L}$ PBS) via the tail vein $4 \mathrm{~h}$ after LPS; ALI group (ALI) mice received the same amount of phosphate-buffered saline (PBS) via the tail vein $4 \mathrm{~h}$ after LPS; and control group (Con) mice were given the same amount of PBS at the corresponding time (Additional file 1: Fig. S1B). To confirm the effect of DCregs on CD4 ${ }^{+} \mathrm{T}$ cells in ALI lungs, we conducted another in vivo experiment. The control group (Con) and ALI group were treated as described above, and mice in the DCreg group (DCreg) received 
DCregs $(500,000$ cells in $150 \mu \mathrm{L}$ PBS) via the tail vein $4 \mathrm{~h}$ after LPS (Additional file 1: Fig. S1C).

To confirm the effect of MSCs on DC migration in ALI mice, the following experiments were performed. ImDCs were labeled with $0.5 \mathrm{mM}$ carboxyfluorescein diacetate succinimidyl ester (CFSE). A total of 1,000,000 labeled cells were injected via the tail vein into wild-type recipient mice before LPS or PBS. The mice were randomly assigned to one of the following three groups ( $\mathrm{n}=6$ mice per group): MSC group (MSC) mice received MSCs (500,000 cells in $150 \mu \mathrm{l}$ PBS) via the tail vein $4 \mathrm{~h}$ after LPS; ALI group (ALI) mice received the same amount of phosphate-buffered saline (PBS) via the tail vein $4 \mathrm{~h}$ after LPS; Control group (Con), mice were given the same amount of PBS at the corresponding time (Additional file 1: Fig. S1D).

To investigate the effect of MSC-mediated inhibition of DCreg production on the pathological damage in ALI mice, the mice were randomly assigned to one of the following two groups ( $\mathrm{n}=6$ mice per group): $\mathrm{MSC}+\mathrm{DAPT}$ group (MSC+DAPT) mice were injected intratracheally with DAPT $(0.3 \mathrm{mg} / \mathrm{kg}) 0.5 \mathrm{~h}$ before LPS and received MSCs $(500,000$ cells in $150 \mu \mathrm{L}$ PBS) via the tail vein $4 \mathrm{~h}$ after LPS [24]; MSC+DMSO group (MSC + DMSO) mice were injected intratracheally with the same amount of DMSO $0.5 \mathrm{~h}$ before LPS and received MSCs $(500,000$ cells in $150 \mu \mathrm{L}$ PBS) via the tail vein $4 \mathrm{~h}$ after LPS; DMSO group (DMSO) mice were injected with DMSO equivalent to DAPT at $0.5 \mathrm{~h}$ before modeling, and were injected with the same amount of PBS with LPS or MSCs at the corresponding time; DAPT group (DAPT) mice were injected with DAPT $0.5 \mathrm{~h}$ before modeling, and injected with the same amount of PBS as LPS or MSCs at the corresponding time (Additional file 1: Fig. S1E). Lymphocytes in monocyte suspensions of lung tissue and peripheral blood were isolated by lymphocyte separation medium density gradient centrifugation. Lung cell isolation and measurement of the accumulation and maturation of cDCs by flow cytometry were performed as previously described [13].

\section{Evaluation of lung edema}

Lung wet weight to body weight (LWW/BW) ratios, which reflect the severity of lung vascular permeability and lung edema, were determined for the control, ALI and MSC groups.

\section{Lung histopathology}

The right upper lobe was embedded in paraffin and sagittally sliced into $5 \mu \mathrm{m}$ thick sections. The sections were stained with hematoxylin and eosin. Edema, alveolar and interstitial inflammation and hemorrhage, atelectasis, necrosis, and hyaline membrane formation were each scored using a 0 - to 4-point scale. The severity of lung injury was calculated as the sum of the scores as previously described [25].

\section{Flow cytometry}

For phenotypic analysis of cell surface marker expression, cells were harvested, resuspended in PBS, incubated for 15 min with FcR blocking reagent, and then incubated for 15 min with PE-, APC-, PE-Cy7-, PerCP-, or FITC-conjugated monoclonal antibodies on ice. DCs were stained with antibodies against CD11c, CD40, CD86, CD11b, MHC-II, CD4, CD44, CD69 and PD-L1 (BD Pharmingen). Mouse IgG1 isotype control antibodies were used in parallel as negative controls. CFSE (BD Pharmingen) was used in DCs or lymphocytes. The stained cells were washed twice, resuspended in cold buffer and then analyzed by flow cytometry (FACSCalibur; NovoCyte), and the results were processed using NovoExpress software. The results are expressed as the percentage of positively stained cells relative to the total cell number.

\section{Mitogen proliferation assay}

The protocol was based on previous mitogen proliferation and mixed lymphocyte culture with minor modifications [16]. CFSE-labeled splenocytes $\left(5 \times 10^{5}\right.$ cells/ well) were cocultured with allogenic DCs (mDCs or MSC-DCs, $5 \times 10^{4}$ cells/well) in a total volume of $0.2 \mathrm{~mL}$ medium in 96-well U-bottom plates.

\section{Western blot analysis}

For the Notch assay, Jagged1, Jagged2, Notch1, Notch2 and Notch3 were measured by Western blot analysis. Proteins were separated by sodium dodecyl sulfate-polyacrylamide gel electrophoresis and transferred to polyvinylidene difluoride (PVDF) membranes. The membranes were incubated with primary antibodies against Jagged1 (1:1000; Abcam), Notch3 (1:1000; Abcam), Jagged2 (1:1000; Cell Signaling), Notch1 (1:1000; Cell Signaling) and Notch2 (1:1000; Cell Signaling) at a 1:1000 dilution at $4{ }^{\circ} \mathrm{C}$ overnight. The membranes were incubated with secondary antibody for $1 \mathrm{~h}$ at room temperature. Immunoblots were visualized using enhanced chemiluminescence (ECL; Thermo Scientific). The expression levels from whole cell extracts were normalized to $\beta$-actin or tubulin (1:1000; Cell Signaling).

\section{Statistical analysis}

All statistical analyses were performed using SPSS 23.0 software and GraphPad Prism 7.0. One-way analysis of variance (ANOVA) or two-tailed Student's t test was used to determine the significance between the groups. The data are expressed as the mean \pm standard deviation (SD). A value of $\mathrm{p}<0.05$ was considered significant. 


\section{Results}

\section{Lung CDCs increase in ALI mice}

We first investigated the percentage of $\mathrm{CD} 11 \mathrm{c}^{+} \mathrm{cDCs}$ in lung tissue in LPS-induced mice by flow cytometry. The percentage of cDCs in ALI mice gradually increased over time after LPS intratracheal injection (especially after $2 \mathrm{~h}$ ) compared with that of the controls (Con) but decreased after $12 \mathrm{~h}$ (Fig. 1a, b), and the degree of pathological damage in the lungs gradually worsened (Fig. 1c), including hemorrhage, increased edema, inflammatory cell infiltration, and increased atelectasis, resulting in a progressively increased lung injury score (Fig. 1d). In addition, ALI mice showed a gradual increase in the percentage of mDCs in lung tissue (especially CD86 ${ }^{+} \mathrm{DCs}$ ) after intratracheal injection of LPS (Fig. 1e, f). The percentage of cDCs and mDCs was positively correlated with the ALI lung pathological injury score (Fig. 1g-i). These results indicate that $\mathrm{cDCs}$, especially mDCs, participate in the progression of ALI pathogenesis.

\section{MSCs inhibit the recruitment and maturation of CDCs in ALI mice and alleviate lung pathological damage}

In view of the significant changes in lung DCs $2 \mathrm{~h}$ after airway injection of LPS, the mice were treated with MSCs $4 \mathrm{~h}$ after LPS administration. The percentage of $\mathrm{cDCs}$ was significantly decreased compared with that of ALI mice $24 \mathrm{~h}$ after MSC treatment (Fig. 2a, b). The proportion of mDCs ( $\mathrm{MHCII}^{+} \mathrm{DCs}$ ) among the lung cDCs of ALI mice was also significantly reduced after MSC treatment (Fig. 2c, d). The percentages of $\mathrm{CD}^{+} \mathrm{T}$ cells and $\mathrm{CD}^{+} 9^{+}$ in $\mathrm{CD}^{+} \mathrm{T}$ cells in the lung were significantly increased in the ALI group and decreased after treatment with MSC (Fig. 2e-g). In addition, after MSC treatment, lung pathological injuries, such as hemorrhage, edema, inflammatory cell infiltration, and atelectasis, were all significantly reduced (Fig. 2i), and the pathological scores of the lung and LWW/BW were also decreased (Fig. 2h, j). Our findings suggest that MSCs reduce ALI lung injury, accompanied by a decrease in the number and maturity of cDCs in the lungs. The in vivo results showed that CFSE-labeled DCs increased in the blood and lung tissues of ALI mice compared with the control group (Fig. 2k, l). After MSC treatment, the number of CFSE-labeled DCs in the blood and lung tissues of ALI mice decreased (Fig. 2m, n).
MSCs induce the production of immunotolerant DCs The in vivo experiments indicated that the $\mathrm{CDCs}$ in the lung were mainly $\mathrm{mDC}$ as early as $2 \mathrm{~h}$ after intratracheal injection of LPS, and MSC treatment reduced the maturity of DCs. Therefore, we further investigated whether MSCs affect the phenotype and function of mDCs through direct contact by in vitro coculture and found that DCs cocultured with MSCs expressed decreased levels of MHCII, CD86, and CD40 compared to those of mDCs, and the effect of MSC on mDCs was not changed even in the LPS environment (Fig. 3a, b). By examining the protein expression of the immunotolerance marker PD-1, it was found that MSCs reduced the expression of PD-1 in mDCs (Fig. 3c, d). A mitogen proliferation assay was performed to verify functional changes in MSC-DCs. CFSE-labeled splenic lymphocytes were used as responders and were cocultured with mDCs and MSC-DCs. The results showed that the ability of MSC-DCs to stimulate lymphocyte proliferation was significantly weaker than that of mDCs (Fig. 3e, f). These results demonstrate that MSCs induce mDCs into immune-tolerant DCs that inhibit lymphocyte proliferation. In addition, we further evaluated the effect of MSC-induced DCregs on the activation of pulmonary $\mathrm{CD} 4^{+} \mathrm{T}$ cells in LPS-ALI mice. The results showed that the expression of $\mathrm{CD} 44^{+} \mathrm{CD} 69^{+}$in pulmonary $\mathrm{CD} 4^{+} \mathrm{T}$ cells was increased in ALI mice but decreased significantly after DCreg treatment (Fig. 3g, i).

\section{The Notch pathway is activated during MSC-induced differentiation of $\mathrm{mDC}$ into DCregs}

The Notch pathway plays an important role in regulating dendritic cell differentiation through direct cell-to-cell contact mechanisms [21]. Previous studies have found that the Notch pathway is activated during MSC-induced tolerance of DCs to inflammation in mice with allergic airway inflammation. To confirm the involvement of the Notch pathway in the induction of DCregs by MSCs, we detected DC Notch receptor protein expression after 3 days of coculture with MSCs. We measured the protein levels of Notch1, 2 and 3 in DCs after coculture by Western blotting. Surprisingly, we found that $\mathrm{mDCs}$ that were cocultured with MSCs contained more Notch2 than mDCs (Fig. 4a, b). The flow cytometry results also showed that the expression of Notch2 in $\mathrm{CD}_{11 c^{+}}$cells was higher than that in DCs after coculture (Fig. 4c, d).

\footnotetext{
(See figure on next page.)

Fig. 1 The percentage of CDCs and mDCs in the lungs of ALI mice and the degree of pathological damage at different times after intratracheal injection of LPS. $\mathbf{a}, \mathbf{b}$ The percentage of CDCs changed with time after intratracheal LPS injection in ALI mice. $\mathbf{c}$, $\mathbf{d}$ Representative tissue sections of lung tissue (hematoxylin and eosin staining; magnification, $\times 200$ ) and pathological lung injury scores from 0 to $24 \mathrm{~h}$. e, $\mathbf{f}$ Expression of MHCII and CD86 in CDCs in the mouse lung cells from 0 to $24 \mathrm{~h}$ after intratracheal LPS injection. $\mathbf{g}-\mathbf{i}$ The correlation between the percentage of $\mathrm{CDCs}$, MHCII cDCs and $\mathrm{CD} 86^{+} \mathrm{CDC}$ and pathological scores was analyzed by Pearson correlation coefficient. The data are presented as the mean \pm SD. ${ }^{*} \mathrm{p}<0.05$ vs. the control group; $n=6$ per group
} 


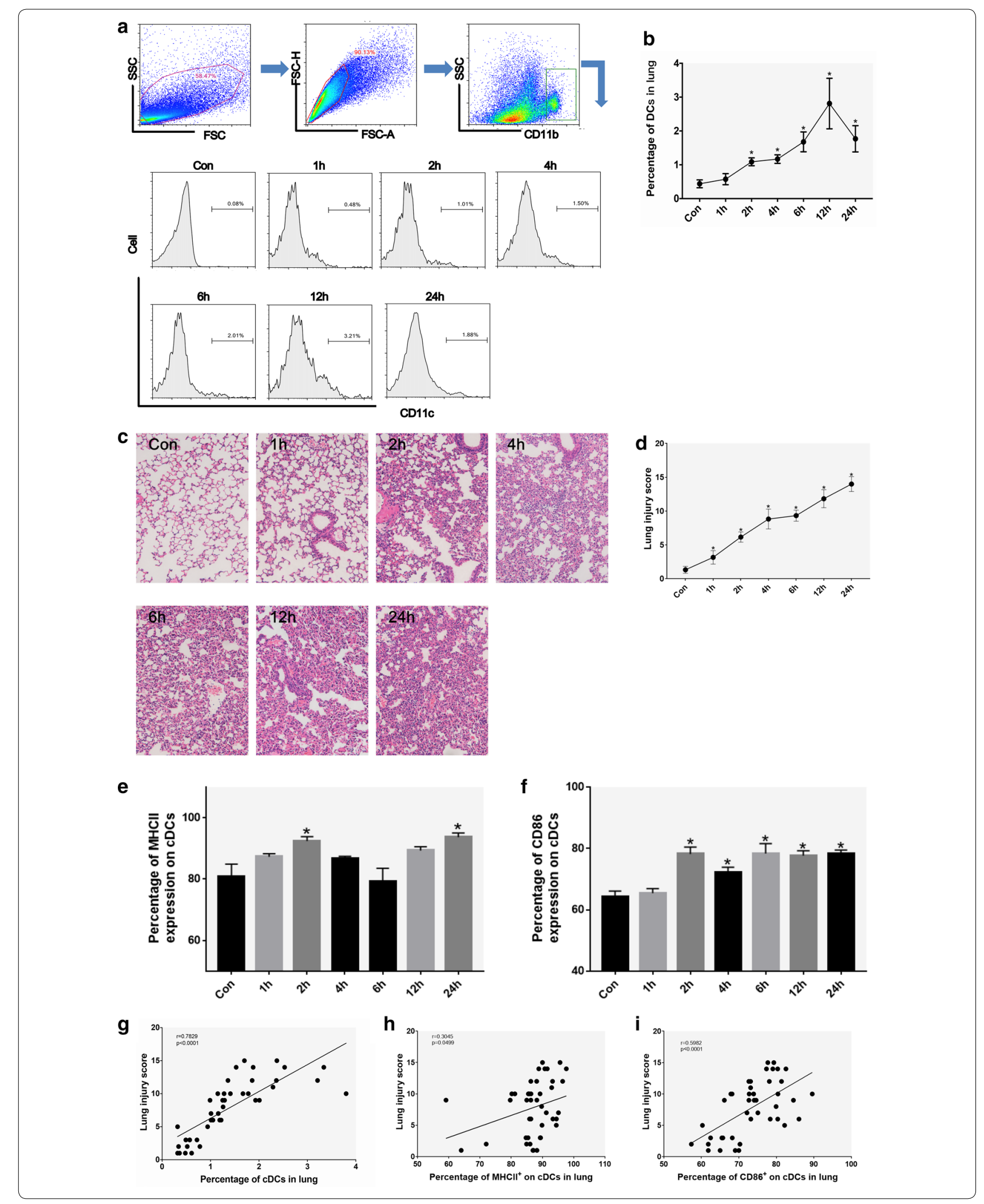


(See figure on next page.)

Fig. 2 Tail vein injection of MSCs inhibited the recruitment and maturation of lung CDCs in ALI mice and improved pulmonary damage. a, b The percentage of lung CDCs in normal, ALI and MSC groups. $\mathbf{c}$, $\mathbf{d}$ The percentage of $\mathrm{MHCll}^{+}$or $\mathrm{CD} 86^{+}$cells in lung $\mathrm{CDCs}$ of mice in normal, ALI and MSC groups. $\mathbf{e}-\mathbf{g}$ The percentages of lung CD4 ${ }^{+} \mathrm{T}$ cells and $\mathrm{CD} 69^{+}$cells in $\mathrm{CD} 4^{+} \mathrm{T}$ cells in the normal, ALI, and MSC groups. $\mathbf{h}$ Lung wet weight to body weight ratio (LWW/BW) of mice in normal group, ALI group and MSC group. $\mathbf{i}, \mathbf{j}$ Histopathological features of lung (hematoxylin and eosin staining; magnification, $\times 200$ ) and lung injury score in the normal, ALI, and MSC groups. $\mathbf{k}$, I The percentage of CFSE-labeled DCs in peripheral blood in normal group, ALI group and MSC group. $\mathbf{m}, \mathbf{n}$ The percentage of CFSE-labeled DCs in the lung of mice in normal group, ALI group and MSC group. The data are presented as the mean $\pm S D$. ${ }^{*} p<0.05$ vs. the control group, ${ }^{\#} p<0.05$ vs. ALI group; $n=6$ per group

Similarly, we also detected the expression of jagged1 and 2 in MSCs, and MSCs expressed more jagged1 protein under LPS stimulation (Fig. 4e, f). The percentage of Notch $2^{+}$DC after rhJagged1 treatment was significantly higher than that of $\mathrm{mDC}$ (Fig. 4g, h). Collectively, these data show that the Notch pathway is activated during MSC-induced differentiation of mDCs into DCregs, which may be an important mechanism by which MSCs regulate $\mathrm{DC}$ function.

\section{MSCs induce the differentiation of $\mathrm{mDCs}$ into DCregs via the Notch signaling pathway}

The Notch pathway plays an important role in regulating dendritic cell differentiation through direct cell-to-cell contact mechanisms. Therefore, we first verified whether recombinant mouse Jagged1 induced $\mathrm{mDC}$ differentiation into immune-tolerant DCs. Jagged1 decreased the expression of DC MHCII, CD86 and CD40, but this effect was offset by a gamma secretase inhibitor (DAPT) (Fig. 5a, b). Subsequently, we determined the DC phenotype induced by MSCs in the presence or absence of a gamma secretase inhibitor (DAPT) by flow cytometry in vitro. In contrast to the results shown in Fig. 3a, b, DAPT increased the expression of MHCII and CD86 in DCs that were cocultured with MSCs (Fig. 5c, d). These data suggest that inhibition of the Notch pathway impairs MSC-induced DCreg production, but the in vivo results are still unclear.

\section{MSCs induced regulatory DCs to attenuate ALI via the notch pathway}

Figure 2 shows that MSC treatment alleviated lung injury and reduced the number and maturity of respiratory cDCs. DCreg generation induced by MSCs was inhibited by DAPT in vitro. To further investigate the role of the Notch pathway in MSC-mediated improvement in lung injury and lung DCs in vivo, the inhibitor DAPT was used. We found that after DAPT intervention, the inhibitory effect of MSCs on $\mathrm{CD}_{11 \mathrm{c}^{+}} 11 \mathrm{~b}^{+} \mathrm{DC}$ recruitment among lung cells was weakened (Fig. 6a, b). Similarly, DAPT inhibition of the NOTCH pathway reversed the effect of MSCs on the lung DC phenotype and increased the antigen-presenting molecule MHCII and costimulatory molecule CD86 (Fig. 6c). In addition, after DAPT treatment, lung tissue pathological injury was significantly aggravated, presenting as increased pulmonary hemorrhage, edema, inflammatory cell infiltration and atelectasis (Fig. 6d). Lung injury score and the LWW/BW were increased (Fig. 6e, f).

\section{Discussion}

In this study, we found significant accumulation and maturation of lung DCs $2 \mathrm{~h}$ after intratracheal injection of LPS, which were positively correlated with the lung pathological injury score. MSCs induce mDCs to differentiate into DCregs, which have low expression of MHCII, CD86 and CD40, by direct cell-cell contact. In addition, we also showed that MSCs activate the Notch pathway by Jagged1 binding and increasing the expression of Notch2 to induce the generation of DCregs. On the other hand, by inhibiting the Notch pathway in vivo and in vitro, the induction of DCregs by MSCs was weakened, and the pulmonary protective effect of MSCs on ALI was reduced. In conclusion, MSCs induce DCreg production by activating the Notch pathway to alleviate acute lung injury.

Previous studies showed that mature DCs increased significantly in the lung tissues of ALI mice, and Fmslike tyrosine kinase 3 pretreatment stimulates lung DC proliferation and maturation, exacerbating lung pathological damage. In contrast, Losartan pretreatment inhibited lung DC proliferation and maturation and alleviated lung damage $[12,13]$. These results indicated that mature DCs play a key role in the pathogenesis of ALI. We found that $\mathrm{CDCs}$ in the lung tissues of ALI mice matured and increased significantly as early as $2 \mathrm{~h}$ after LPS injection and continued to increase up to $12 \mathrm{~h}$. Although we found a positive correlation between the percentage and maturity of cDCs and the lung pathological injury score, the contribution of intervention with mature DC function to lung protection in ALI should be interpreted cautiously. On the one hand, the evidence is that LPS can stimulate the mature activation of DC, and mature DCs express a large number of MHC II and CD80, CD86 and other co-stimulating molecules, inducing the activation of naive $\mathrm{T}$ cells and differentiating into effector $\mathrm{T}$ cells [26], which aggravate the inflammatory response of ALI [27]. Therefore, regulating the functions of mature DCs may 


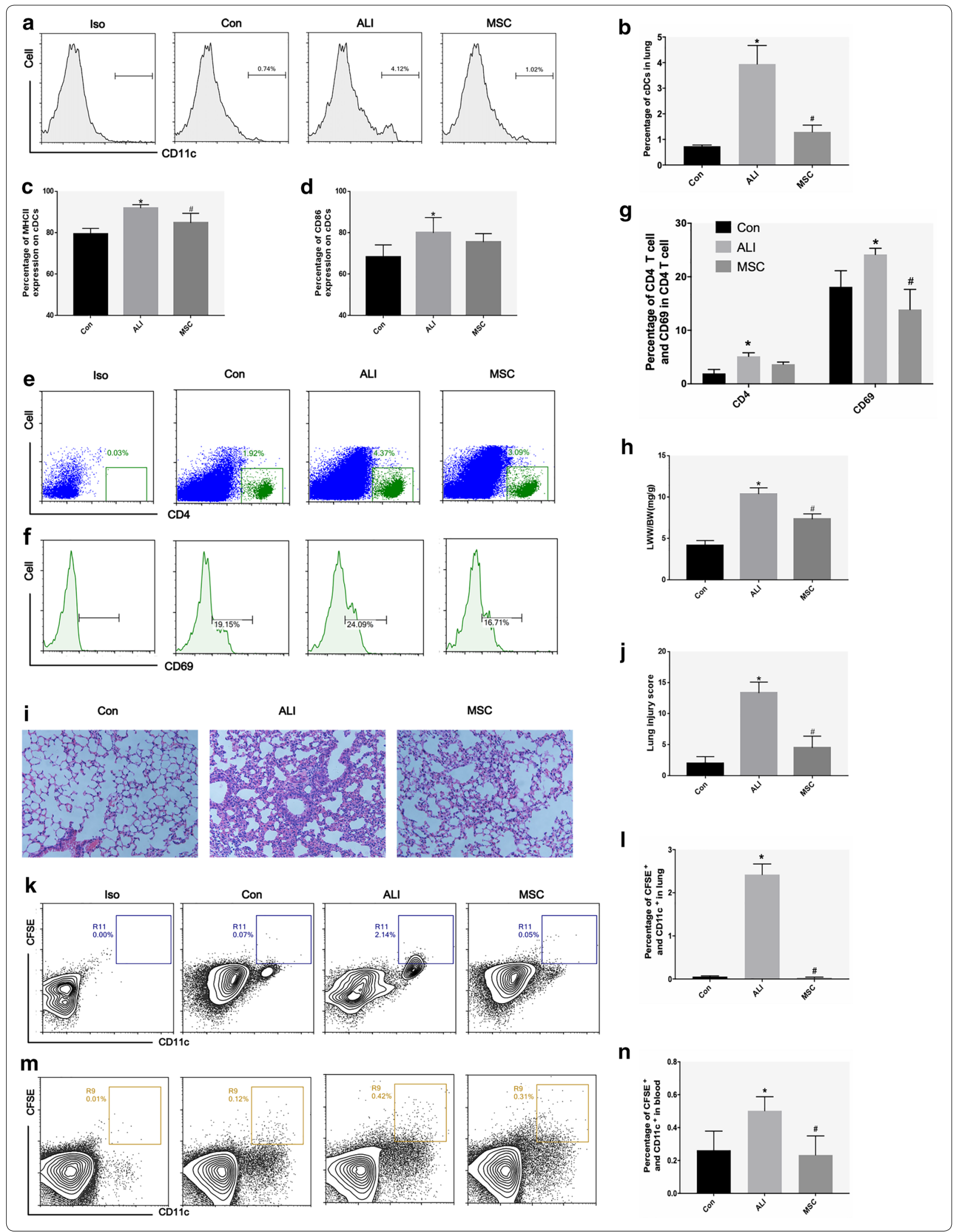


(See figure on next page.)

Fig. 3 MSCs induced the production of immunotolerant DCs by cell-cell interactions. $\mathbf{a}, \mathbf{b}$ The percentages of $\mathrm{MHCII}^{+}, \mathrm{CD} 86^{+}$and $\mathrm{CD} 40^{+}$ based on $C D 11 c^{+} D C$ gate in $\mathrm{mDC}, \mathrm{MSC}+\mathrm{mDC}$ and MSC + mDC + LPS groups. $\mathbf{c}$, d The percentages of PD-L1 + DCs based on CD11C+ DC gate in $\mathrm{mDC}, \mathrm{MSC}+\mathrm{mDC}$ and $\mathrm{MSC}+\mathrm{mDC}+\mathrm{LPS}$ groups. e, $\mathbf{f}$ The percentage of lymphocyte proliferation in $\mathrm{mDC}$ group, MSC + $\mathrm{mDC}$ group and $M S C+m D C+$ LPS group. $\mathbf{g}, \mathbf{h}$ The percentages of $C D 44^{+} C D 69^{+}$based on $C D 4^{+}$T cell gate in $\mathrm{mDC}, \mathrm{MSC}+\mathrm{mDC}$ and $\mathrm{MSC}+\mathrm{mDC}+\mathrm{LPS}$ groups. $n=3$ per group; the data are presented as the mean $\pm S D$. $\mathbf{b}, \mathbf{d}^{*} \mathrm{p}<0.05$ vs. the $m D C$ group, ${ }^{*} p<0.05$ vs. MSC $+m D C$ group; $\mathbf{f}^{*} p<0.05$ vs. the Lym group, ${ }^{\#} p<0.05$ vs. the mDC/lym group; $\boldsymbol{h}{ }^{*} p<0.05$ vs. the Con group, ${ }^{\#} p<0.05$ vs. the ALI group

be crucial in LPS-induced ALI treatment. On the other hand, respiratory DCs sample microorganisms and particulates from the respiratory tract and present them to $\mathrm{T}$ cells to initiate an adaptive immune response to clear bacteria in the lungs [28]. In fact, the regulation of DC therapy for bacteria-induced ARDS requires finding a balance between the elimination of pathogens and the suppression of organ damage caused by excessive inflammatory responses. However, in this study, we observed the effect and mechanism of MSC on lung DCs in LPSinduced-ALI mice without considering the factor of bacteria.

MSCs show strong immunoregulatory functions by suppressing $\mathrm{T}$ cell proliferation and activation, inducing regulatory $\mathrm{T}$ cells, inhibiting $\mathrm{B}$ cell function, or promoting the phagocytic activity of macrophages [8-10]. However, whether DCs are regulated by MSCs in the ALI microenvironment is not known. Our findings revealed that MSCs significantly downregulated the percentage and maturity of cDCs in ALI mice and alleviated lung injury. According to the findings of this study, the percentage of mDCs increased significantly in ALI mice $2 \mathrm{~h}$ after LPS administration but decreased after treatment with MSCs, suggesting that MSCs induce cDCs from mature phenotypes to differentiate into immature phenotypes, alleviating lung injury and reducing pulmonary edema. To support this conclusion, we performed in vitro experiments that showed that $\mathrm{mDC}$ expression of PD-L1, the antigen presenting molecule MHCII and costimulatory molecules CD86 and CD40 decreased significantly after 3 days of coculture with MSCs, and still maintained stable phenotypes in the LPS microenvironment, which was consistent with the previous 7 days of coculture [16]. The expression levels of MHCII, CD86 and CD40 determine whether DCs can capture and process antigens and deliver them to $T$ cells, which affects the proliferation and activation of $\mathrm{T}$ cells $[29,30]$, and PD-1 is necessary for DC-mediated induction of regulatory $\mathrm{T}$ cells and tolerance [31]. We confirmed that the proliferation and activation of $\mathrm{T}$ cells that were stimulated by DCs after coculture with MSCs were decreased, and we also found that treatment with MSC reduced the number and percentage activation of $\mathrm{CD} 4^{+} \mathrm{T}$ cells in the lung of ALI mice.
Studies have reported that after MSC culture with DCs, the expression of CCR7 was decreased after DC stimulation, and migration to CCL19 or CCL21 was also significantly reduced [15, 32]. Analysis of respiratory dendritic cell subsets revealed significantly reduced lung DC infiltration in MSC-treated mice with acute lung injury induced by Klebsiella pneumoniae [33], and Chiesa also reported that MSCs inhibit DC migration to lymph nodes [34]. Consistent with these results, we found that lung DCs were significantly reduced in ALI mice that were treated with MSCs, which may be due to MSC-mediated inhibition of DC migration. The results of in vivo experiments showed that CFSE-labeled DCs had increased retention times in ALI mouse blood, indicating that MSCs reduced the retention of CFSE-labeled DCs in ALI mouse blood, resulting in reduced migration of DCs to the lungs.

The Notch signaling pathway controls cell proliferation, apoptosis, survival and differentiation during cell development and homeostasis [21, 35-38]. MSCs induced a semimature DC phenotype that required jagged1 to activate Notch signaling for the expansion of regulatory $\mathrm{T}$ cells, reducing the pathology in a mouse model of allergic airway inflammation [19]. Consistent with these results, our study shows that under LPS stimulation, MSCs expressed more jagged1, and both MSCs and recombinant jagged1 induced the generation of DCregs. Jagged1/Notch2 signal activation is closely related to cell regeneration and immune cell regulation $[39,40]$. Previous studies have shown that promoting the expression of $\mathrm{NOTCH} 2$ reduces the efficiency of DC presentation of MHC class II-restricted antigens and limits the strength of $\mathrm{CD} 4^{+} \mathrm{T}$ cell activation [41]. This study similarly found that the expression of Notch2 receptor protein was significantly increased in MSC-treated DCs or recombinant jagged1-treated DCs. Therefore, these results suggest that the Notch pathway is involved in the mechanism by which MSCs induce $\mathrm{mDC}$ immune tolerance. In this study, the expression of costimulatory molecules in DCs and functional markers of $\mathrm{T}$ cells that were stimulated by DCs showed that MSCs induced DCreg production.

$\gamma$-Secretase inhibitors are a class of small molecular compounds that target the Notch pathway and have been used in preclinical and clinical trials to treat a variety of diseases [42, 43]. Gamma-secretase inhibitors have been 
a
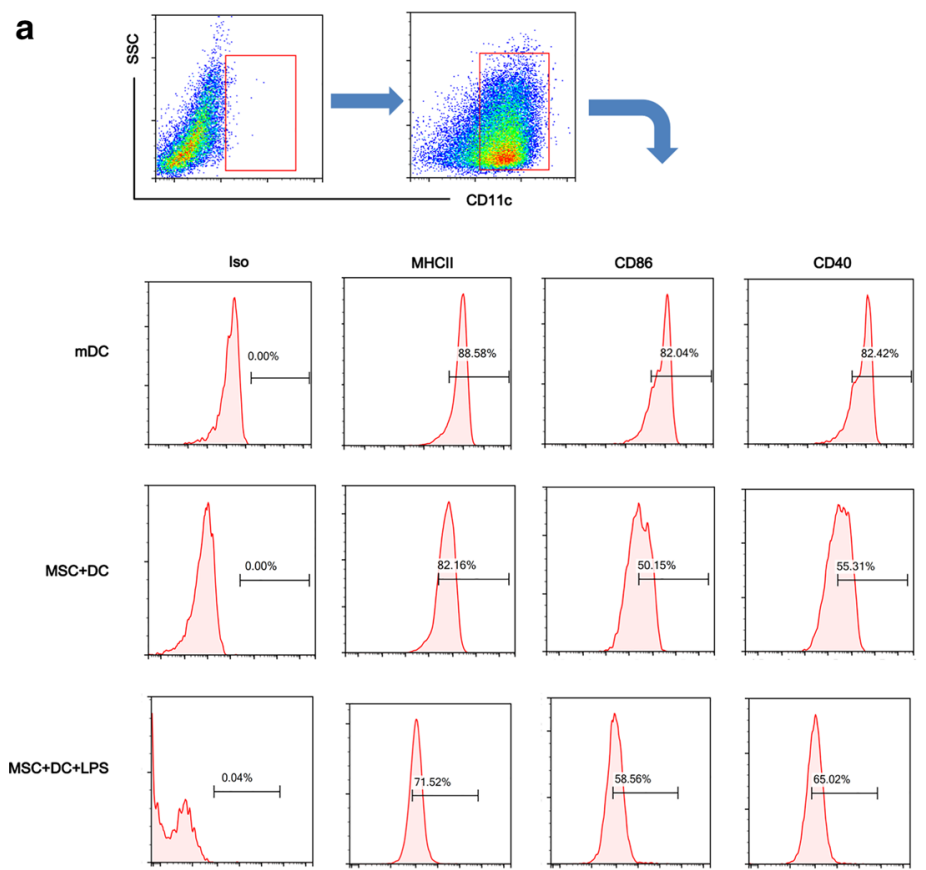

b

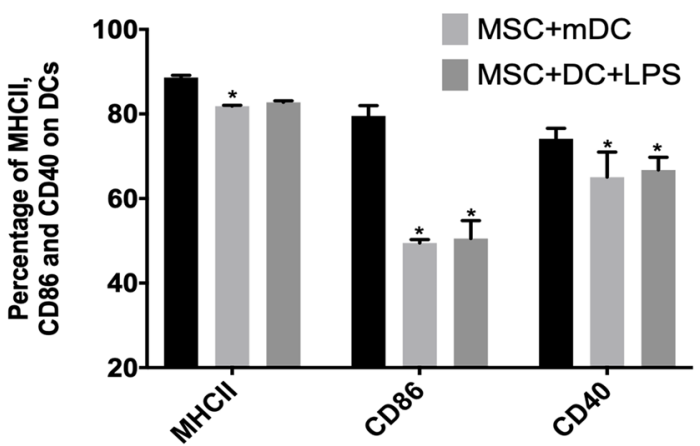

C
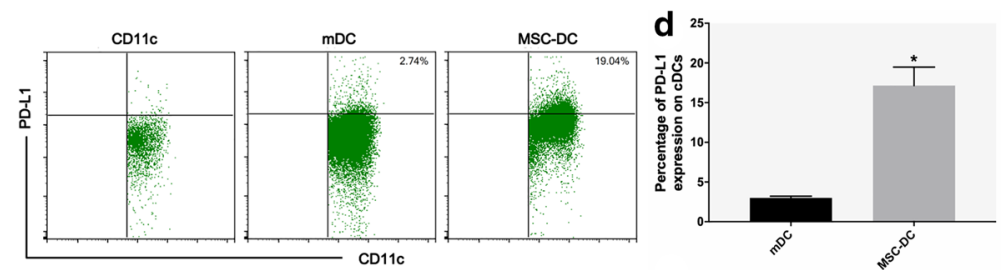

e
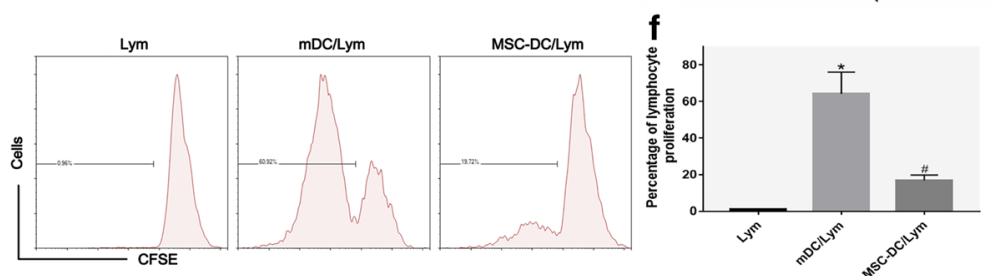

g

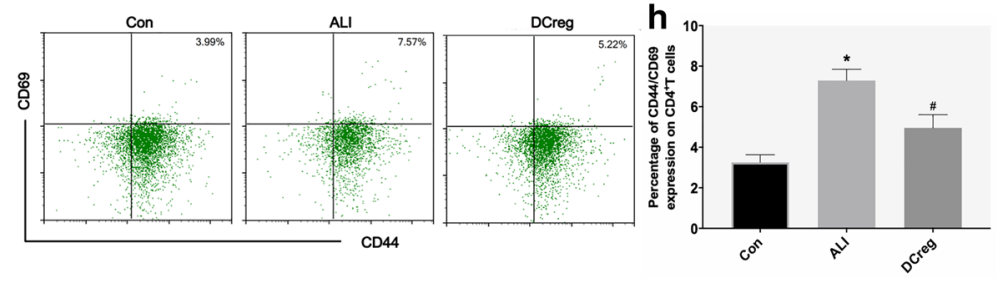




\section{a \\ c}
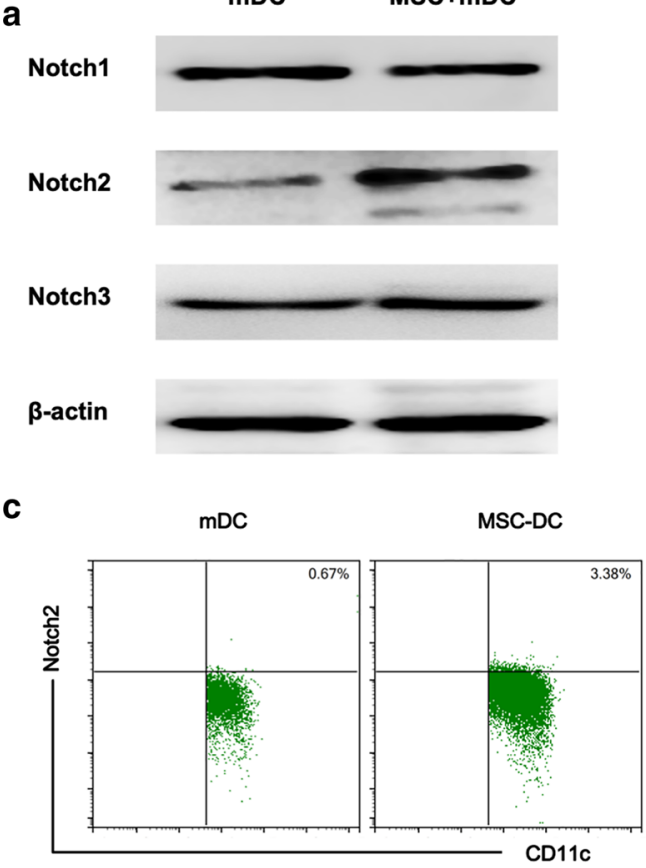

e

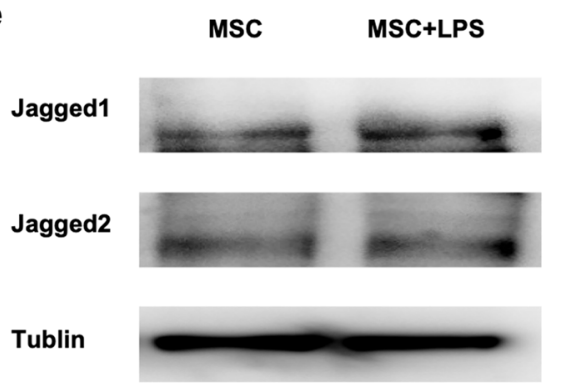

g

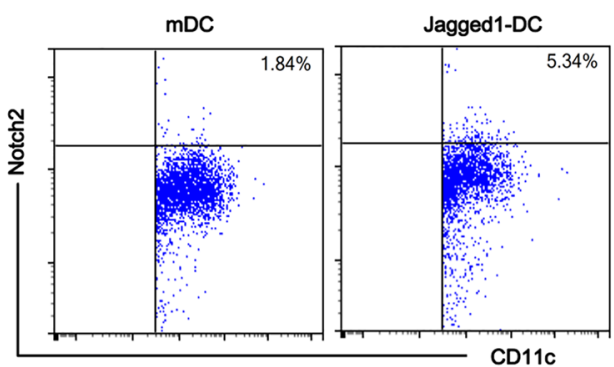

b

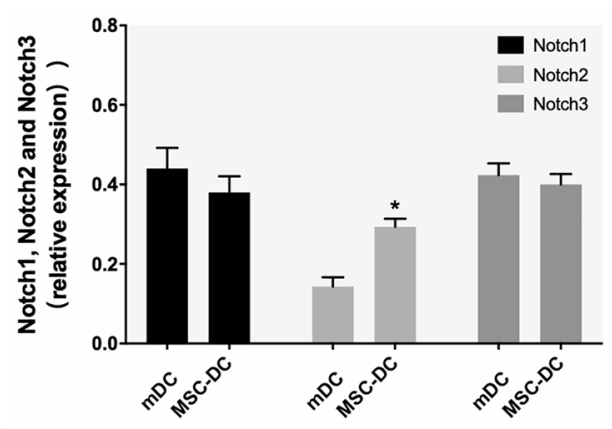

d

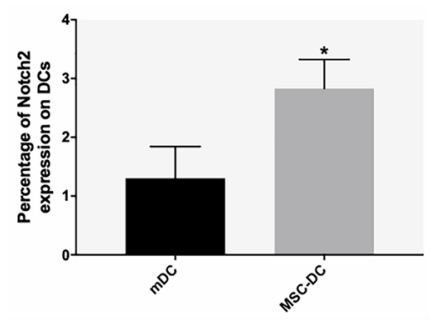

f

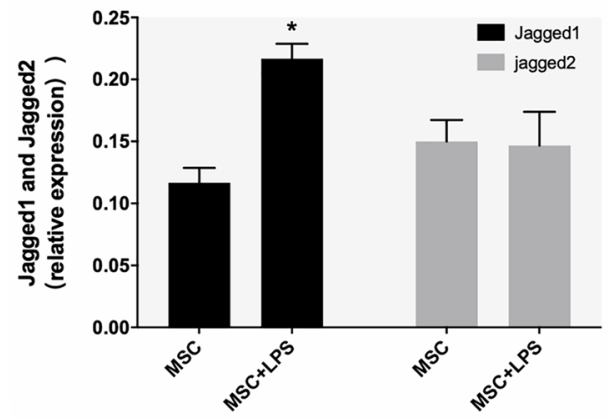

h

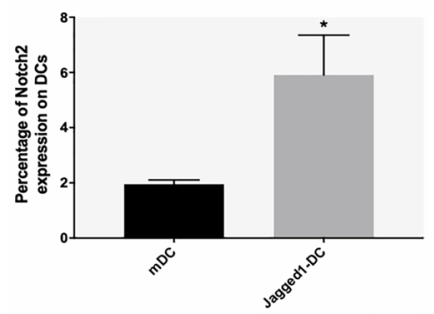

Fig. 4 The Notch pathway is activated during the MSC-induced differentiation of mDCs into DCregs. a, b The expression of Notch1, Notch2 and Notch3 protein levels in DCs that were cultured with or without MSCs for $72 \mathrm{~h}$ was evaluated using Western blot analysis. c, $\mathbf{d}$ The percentage of Notch2-positive cells in CD11 $\mathrm{c}^{+}$DCs that were cultured with or without MSCs for $72 \mathrm{~h}$ was detected by flow cytometry. $\mathbf{e}$, f The expression of Jagged 1 and Jagged 2 protein levels in MSCs that were cultured with or without LPS for $24 \mathrm{~h}$ was evaluated using Western blot analysis. $\mathbf{g}, \mathbf{h}$ The percentage of Notch2-positive cells in CD11 $c^{+}$DCs that were cultured with or without rhjagged 1 for $72 \mathrm{~h}$ was detected by flow cytometry. $\mathrm{n}=3, \mathbf{b}$, $\mathbf{d}$ and $\mathbf{h}{ }^{*} p<0.05$ versus $\mathrm{mDC} ; \mathbf{f}{ }^{*} p<0.05$ versus MSC; the data are expressed as the mean \pm SD

shown to attenuate neurogenic acute lung injury in rats [44]. This study found that MSCs reduced the expression of DC costimulatory molecules and functional markers, which were blocked by the $\gamma$-secretase inhibitor DAPT. Therefore, we performed in vivo experiments and confirmed that induction of tolerant DCs is a key link in 
a

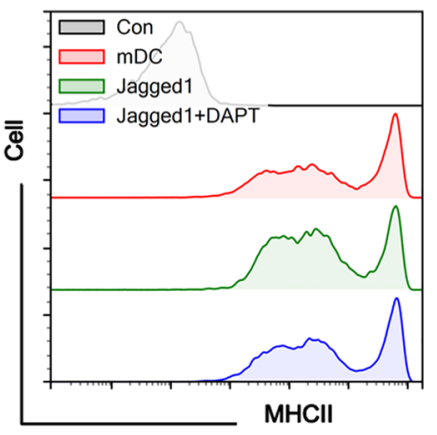

b

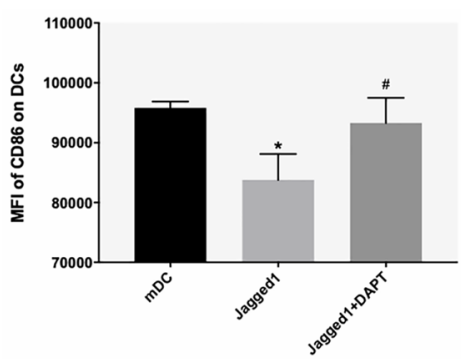

C

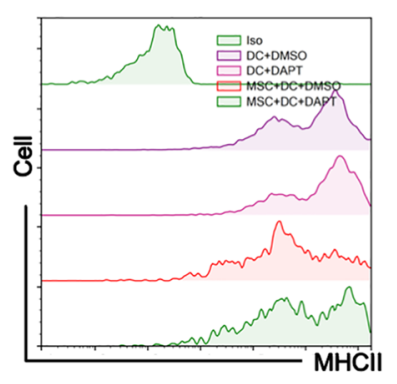

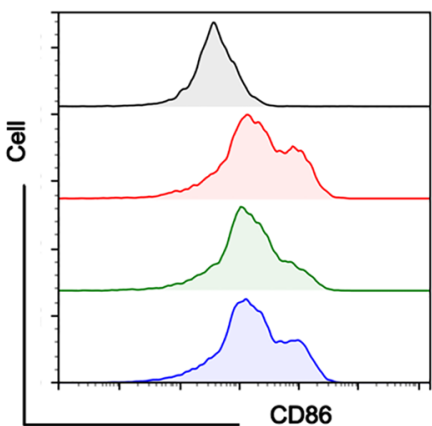
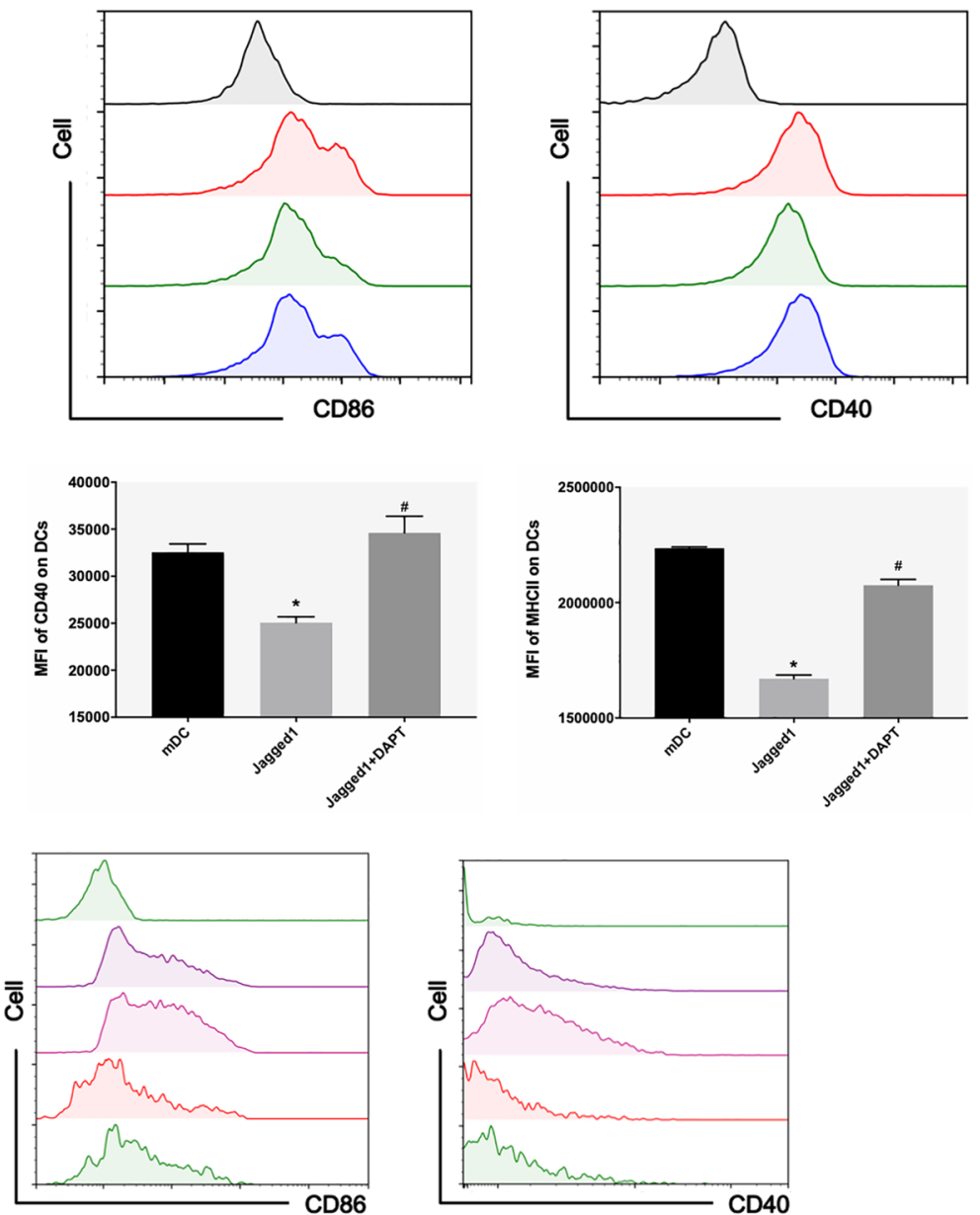

d

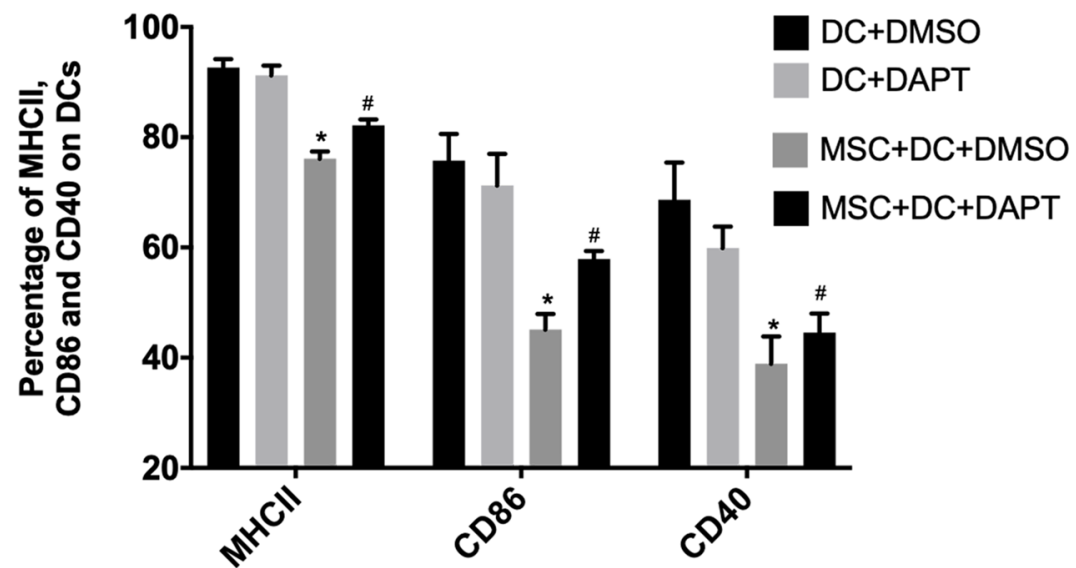

Fig. 5 MSCs induce the differentiation of mDCs into DCregs via the Notch signaling pathway. $\mathbf{a}, \mathbf{b}$ The percentages of MHCII+, $\mathrm{CD}^{+} 6^{+}$and $\mathrm{CD} 4 \mathrm{O}^{+}$

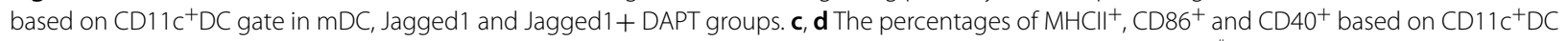
gate in DC+DMSO, DC + DAPT, MSC+DC+DMSO and MSC+DC+DAPT groups. $n=3, \mathbf{b} * \mathrm{p}<0.05$ versus mDC, ${ }^{*} \mathrm{p}<0.05$ versus Jagged1; $\mathbf{d}$ ${ }^{*} \mathrm{p}<0.05$ versus MSC + DC + DMSO; the data are expressed as the mean \pm SD 


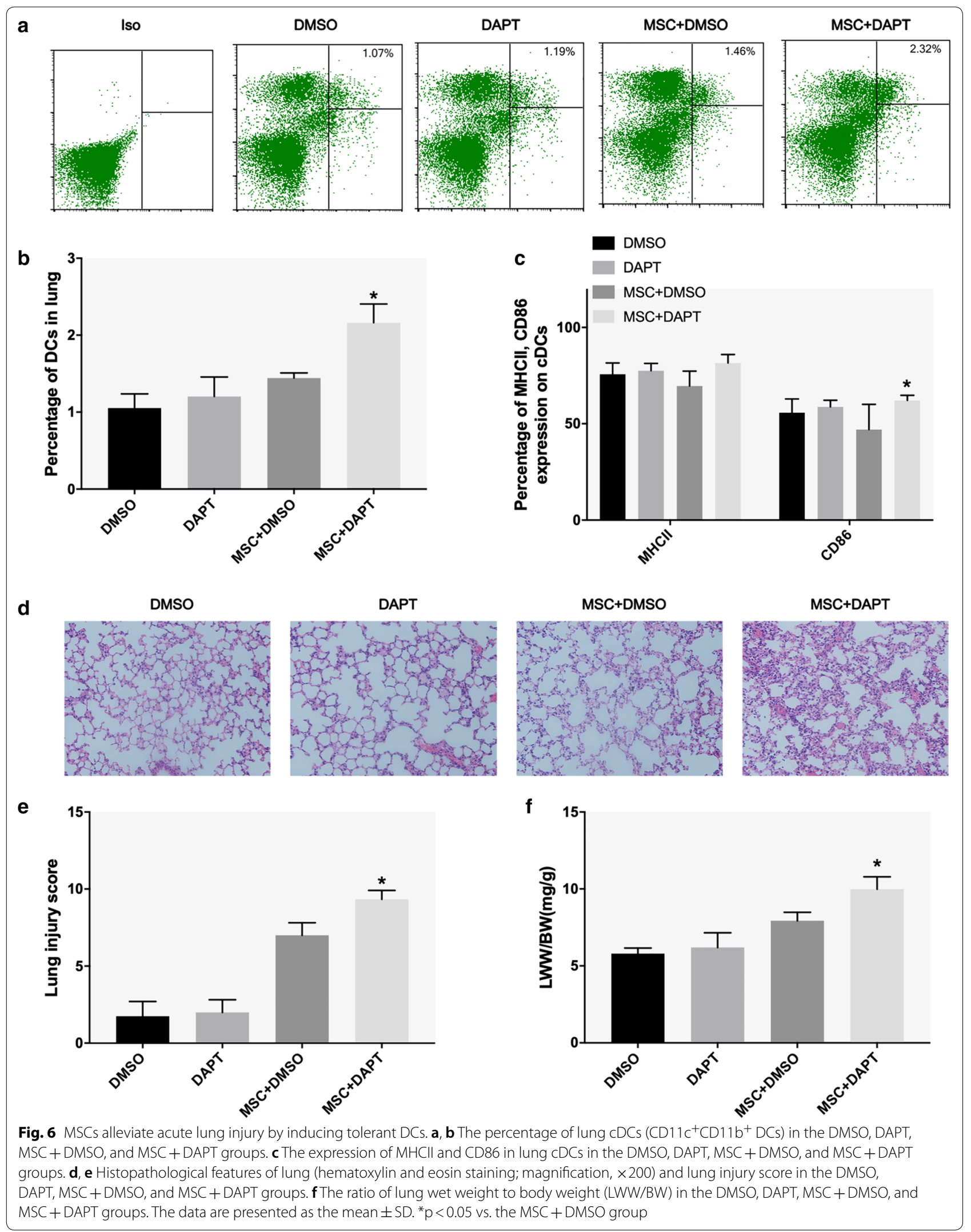


MSC-mediated alleviation of lung pathological damage by inhibiting the Notch pathway. These data suggest that MSCs induce tolerant DCs by activating the Notch pathway to alleviate acute lung injury.

The LPS-induced ALI model has some limitations compared with the bacteria-induced animal model. LPS is a potent agent that activates the innate immune response via the TLR4 pathway, and its use provides information about the effects of host inflammatory response, which occurs in bacterial infections [45]. Many previous studies selected LPS-induced ALI model to study the function of immune cells in ARDS $[46,47]$. In addition to endotoxins, gram-negative bacteria (E. coli) also continue to produce a variety of virulence factors such as adhesin, exotoxin and type III secretion system. The adhesin produced by bacteria mediates the adhesion between bacteria and epithelial cells [48]. Bacteria produce potent cytotoxic exotoxins [49] as well as utilize the type III secreting system to directly cause epithelial cell lysis [50]. This is consistent with Wiener-Kronish's findings that LPS treatment does not cause the severe endothelial injury that occurs in ARDS [51]. LPS binds to specific LPS binding proteins to form a complex, which activates the CD14/TLR4 receptor structure mostly on the surface of immune cells, such as monocytes, macrophages, and dendritic cells, triggering the production of inflammatory mediators [52]. This study focused on the effect of MSC treatment on DC function in ALI, so LPS-induced animal model was selected. In addition, LPS is easy to administer and has little direct toxicity to cultured cells in vitro [45].

\section{Conclusions}

This study demonstrated that the recruitment and maturation of lung DCs is an important process in early acute lung injury. The induction of tolerant dendritic cells is a crucial part of MSC-mediated alleviation of early acute lung injury, and this process is closely related to activation of the Notch pathway. These findings provide new insights into the role of MSCs in lung injury repair.

\section{Supplementary information}

Supplementary information accompanies this paper at https://doi. org/10.1186/s12967-020-02410-z.

Additional file 1: Fig. S1. Time schedule of drug or cell injections in vivo. (A) Changes of lung DC at different time after intratracheal injection of LPS: time schedule for drug or cell injection. (B) Effect of MSC therapy on lung DCs in ALI mice: time schedule for drug or cell injection. (C) Effects of DCreg therapy on the activation of $C D 4^{+} T$ cells in the lungs of ALI mice: time schedule for drug or cell injection. (D) Effect of MSCs on DC migration from peripheral blood to lung in ALI mice: time schedule for drug or cell injection. (E) Effect of DAPT on the regulation of lung DC function by MSC in ALI mice:time schedule for drug or cell injection.

\section{Abbreviations}

ARDS: Acute respiratory distress syndrome; DCs: Dendritic cells; ALl: Acute lung injury; CDCs: Conventional DCs; DCregs: Regulatory DCs; imDCs: Immature DCs; mDCs: Mature DCs; MSCs: Mesenchymal stem cells; LPS: Lipopolysaccharide; PD-L1: Programmed death ligand 1; BM: Bone marrow; FBS: Fetal bovine serum; GM-CSF: Granulocyte-macrophage colony- stimulating factor; IL-4: Interleukin-4; LWW/BW: Lung wet weight to body weight ratio; CFSE: Carboxyfluorescein diacetate succinimidyl ester; PVDF: Polyvinylidene difluoride; PBS: Phosphate-buffered saline; ANOVA: Analysis of variance; SD: Standard deviation.

\section{Acknowledgements}

We would like to thank Dr. Zhenxing Chen, Feng Liu and Fei Peng for their technical support regarding the injection of drugs into the tail vein and intratracheal injection in mice, and Dr. Cuilin Chu for her guidance on the manuscript of this article.

\section{Authors' contributions}

Z-HL, LL and S-SM participated in the collection and assembly of data, data analysis and interpretation, and manuscript writing. WC and S-WF participated in acquisition, analysis, and interpretation of data. Z-HL, LL, J-FX participated in the collection and assembly of the data and review of the manuscript. YY and $\mathrm{H}-\mathrm{BQ}$ participated in the design and supervision of research. LL and F-MG conceived of the study, performed the statistical analysis, and helped to draft the manuscript. All authors read and approved the final manuscript.

\section{Funding}

This study was supported by Clinical Science and Technology Specific Projects of Jiangsu Province [Grant number BE2018743], National Natural Science Foundation of China [Grant numbers 81871602, 81870066, 81670074], Natural Science Foundation of Jiangsu Province (BK20181271), Jiangsu Provincial Medical Youth Talent (QNRC 2016807), Fundamental Research Funds for the Central Universities, Fundamental Research Funds for Southeast University (2242020K40169) and Third Level Talents of the "333 High Level Talents Training Project" in the fifth phase in Jiangsu (LGY2016051).

\section{Availability of data and materials}

Not applicable.

Ethics approval and consent to participate

This study was approved by the Southeast University Ethics Committee (Protocol number 20170105007).

\section{Consent for publication}

Not applicable.

\section{Competing interests}

The authors declare that they have no competing interests.

Received: 29 February 2020 Accepted: 6 June 2020

Published online: 16 June 2020

\section{References}

1. Bellani G, Laffey JG, Pham T, et al. Epidemiology, patterns of care, and mortality for patients with acute respiratory distress syndrome in intensive care units in 50 countries. JAMA. 2016;315(8):788-800.

2. Han J, LiY, LiY. Strategies to enhance mesenchymal stem cell-based therapies for acute respiratory distress syndrome. Stem Cells Int. 2019;2019:5432134.

3. Lin $S$, Wu H, Wang C, Xiao Z, Xu F. Regulatory T cells and acute lung injury: cytokines, uncontrolled inflammation, and therapeutic implications. Front Immunol. 2018;9:1545.

4. Bersten AD, Edibam C, Hunt T, Moran J. Incidence and mortality of acute lung injury and the acute respiratory distress syndrome in three Australian States. Am J Respir Crit Care Med. 2002;165(4):443-8.

5. Shaw TD, McAuley DF, O'Kane CM. Emerging drugs for treating the acute respiratory distress syndrome. Expert Opin Emerg Drugs. 2019;24(1):29-41. 
6. Chen QH, Liu AR, Qiu HB, Yang Y. Interaction between mesenchymal stem cells and endothelial cells restores endothelial permeability via paracrine hepatocyte growth factor in vitro. Stem Cell Res Ther. 2015;6:44.

7. Cai SX, Liu AR, Chen S, et al. Activation of Wnt/beta-catenin signalling promotes mesenchymal stem cells to repair injured alveolar epithelium induced by lipopolysaccharide in mice. Stem Cell Res Ther. 2015;6:65.

8. Pajarinen J, Lin T, Gibon E, et al. Mesenchymal stem cell-macrophage crosstalk and bone healing. Biomaterials. 2019;196:80-9.

9. Palomares Cabeza V, Hoogduijn MJ, Kraaijeveld R, et al. Pediatric mesenchymal stem cells exhibit immunomodulatory properties toward allogeneic T and B cells under inflammatory conditions. Front Bioeng Biotechnol. 2019;7:142.

10. Lee KC, Lin HC, Huang YH, Hung SC. Allo-transplantation of mesenchymal stem cells attenuates hepatic injury through ILIRa dependent macrophage switch in a mouse model of liver disease. J Hepatol. 2015;63(6):1405-12.

11. Li X, Dong Y, Yin H, Qi Z, Wang D, Ren S. Mesenchymal stem cells induced regulatory dendritic cells from hemopoietic progenitor cells through Notch pathway and TGF-beta synergistically. Immunol Lett. 2020;222:49-57.

12. Liu J, Zhang PS, Yu Q, et al. Losartan inhibits conventional dendritic cell maturation and Th1 and Th17 polarization responses: novel mechanisms of preventive effects on lipopolysaccharide-induced acute lung injury. Int J Mol Med. 2012;29(2):269-76.

13. Dong L, He HL, Lu XM, Yang Y, Qiu HB. Modulation of FLT3 signaling targets conventional dendritic cells to attenuate acute lung injury. APMIS Acta Pathol Microbiol Immunol Scand. 2012;120(10):808-18.

14. Jo H, Eom YW, Kim HS, Park HJ, Kim HM, Cho MY. Regulatory dendritic cells induced by mesenchymal stem cells ameliorate dextran sodium sulfate-induced chronic colitis in mice. Gut Liver. 2018;12(6):664-73.

15. English K, Barry FP, Mahon BP. Murine mesenchymal stem cells suppress dendritic cell migration, maturation and antigen presentation. Immunol Lett. 2008;115(1):50-8.

16. Zhang B, Liu R, Shi D, et al. Mesenchymal stem cells induce mature dendritic cells into a novel Jagged-2-dependent regulatory dendritic cell population. Blood. 2009;113(1):46-57.

17. Deng Y, Yi S, Wang G, et al. Umbilical cord-derived mesenchymal stem cells instruct dendritic cells to acquire tolerogenic phenotypes through the IL-6-mediated upregulation of SOCS1. Stem Cells Dev. 2014;23(17):2080-92.

18. Li YP, Paczesny S, Lauret E, et al. Human mesenchymal stem cells license adult CD34+ hemopoietic progenitor cells to differentiate into regulatory dendritic cells through activation of the Notch pathway. J Immunol (Baltimore, Md: 1950). 2008;180(3):1598-608.

19. Cahill EF, Tobin LM, Carty F, Mahon BP, English K. Jagged-1 is required for the expansion of $\mathrm{CD} 4+\mathrm{CD} 25+\mathrm{FoxP} 3+$ regulatory T cells and tolerogenic dendritic cells by murine mesenchymal stromal cells. Stem Cell Res Ther. 2015;6:19.

20. Chen Y, Lian XH, Liao LY, Liu YT, Liu SL, Gao Q. Transplantation of bone marrow mesenchymal stem cells alleviates spinal cord injury via inhibiting Notch signaling. Eur Rev Med Pharmacol Sci. 2019;23(3 Suppl):31-8.

21. Cheng P, Nefedova Y, Miele L, Osborne BA, Gabrilovich D. Notch signaling is necessary but not sufficient for differentiation of dendritic cells. Blood. 2003;102(12):3980-8.

22. Lutz MB, Kukutsch N, Ogilvie AL, et al. An advanced culture method for generating large quantities of highly pure dendritic cells from mouse bone marrow. J Immunol Methods. 1999;223(1):77-92.

23. Luo X, Xu L, Liu L, Li Y, Tan H. Notch inhibition enhances graft-versusleukemia while reducing graft-versus-host disease. Eur J Pharmacol. 2019;843:226-32.

24. Zeng Z, Wang L, Ma W, et al. Inhibiting the Notch signaling pathway suppresses Th17-associated airway hyperresponsiveness in obese asthmatic mice. Lab Invest. 2019;99:1784-94.

25. Hu S, Li J, Xu X, et al. The hepatocyte growth factor-expressing character is required for mesenchymal stem cells to protect the lung injured by lipopolysaccharide in vivo. Stem Cell Res Ther. 2016;7(1):66.

26. Gutcher I, Becher B. APC-derived cytokines and T cell polarization in autoimmune inflammation. J Clin Invest. 2007;117(5):1119-27.

27. Imam F, Al-Harbi NO, Al-Harbi MM, et al. Diosmin downregulates the expression of T cell receptors, pro-inflammatory cytokines and
NF-kappaB activation against LPS-induced acute lung injury in mice. Pharmacol Res. 2015;102:1-11.

28. Holt PG, Stumbles PA. Characterization of dendritic cell populations in the respiratory tract. J Aerosol Med. 2000;13(4):361-7.

29. Tamoutounour S, Han SJ, Deckers J, et al. Keratinocyte-intrinsic MHCII expression controls microbiota-induced Th1 cell responses. Proc Natl Acad Sci USA. 2019;116(47):23643-52.

30. van Gool SW, Barcy S, Devos S, et al. CD80 (B7-1) and CD86 (B7-2): potential targets for immunotherapy? Res Immunol. 1995;146(3):183-96.

31. Yogev N, Frommer F, Lukas D, et al. Dendritic cells ameliorate autoimmunity in the CNS by controlling the homeostasis of PD-1 receptor(+) regulatory T cells. Immunity. 2012;37(2):264-75.

32. Jung YJ, Ju SY, Yoo ES, et al. MSC-DC interactions: MSC inhibit maturation and migration of BM-derived DC. Cytotherapy. 2007;9(5):451-8.

33. Hackstein H, Lippitsch A, Krug P, et al. Prospectively defined murine mesenchymal stem cells inhibit Klebsiella pneumoniae-induced acute lung injury and improve pneumonia survival. Respir Res. 2015;16:123.

34. Chiesa S, Morbelli S, Morando S, et al. Mesenchymal stem cells impair in vivo T-cell priming by dendritic cells. Proc Natl Acad Sci USA. 2011;108(42):17384-9.

35. Vieceli Dalla Sega F, Fortini F, Aquila G, Campo G, Vaccarezza M, Rizzo P. Notch signaling regulates immune responses in atherosclerosis. Front Immunol. 2019;10:1130.

36. Radtke F, Fasnacht N, Macdonald HR. Notch signaling in the immune system. Immunity. 2010;32(1):14-27.

37. Ionescu L, Byrne RN, van Haaften T, et al. Stem cell conditioned medium improves acute lung injury in mice: in vivo evidence for stem cell paracrine action. Am J Physiol Lung Cell Mol Physiol. 2012;303(11):L967-77.

38. Cheng P, Nefedova Y, Corzo CA, Gabrilovich DI. Regulation of dendriticcell differentiation by bone marrow stroma via different Notch ligands. Blood. 2007;109(2):507-15.

39. Chen BL, Chen YQ, Ma BH, et al. Tetrahydrocurcumin, a major metabolite of curcumin, ameliorates allergic airway inflammation by attenuating Th2 response and suppressing the IL-4Ralpha-Jak1-STAT6 and Jagged1/ Jagged2 -Notch1/Notch2 pathways in asthmatic mice. Clin Exp Allergy. 2018:48(11):1494-508.

40. Nakano $Y$, Nakao S, Sumiyoshi $H$, et al. Identification of a novel alphafetoprotein-expressing cell population induced by the Jagged $1 /$ Notch2 signal in murine fibrotic liver. Hepatol Commun. 2017;1 (3):215-29.

41. Briseno CG, Satpathy AT, Davidson JT, et al. Notch2-dependent DC2s mediate splenic germinal center responses. Proc Natl Acad Sci USA. 2018;115(42):10726-31.

42. Pine SR. Rethinking gamma-secretase inhibitors for treatment of non-small-cell lung cancer: is Notch the target? Clin Cancer Res. 2018;24(24):6136-41.

43. Augelli-Szafran CE, Wei HX, Lu D, et al. Discovery of notch-sparing gamma-secretase inhibitors. Curr Alzheimer Res. 2010;7(3):207-9.

44. Lin HJ, Hsu CC, Chio CC, et al. Gamma-secretase inhibitors attenuate neurotrauma and neurogenic acute lung injury in rats by rescuing the accumulation of hypertrophic microglia. Cell Physiol Biochem. 2017:44(5):1726-40.

45. Matute-Bello G, Frevert CW, Martin TR. Animal models of acute lung injury. Am J Physiol Lung Cell Mol Physiol. 2008;295(3):L379-99.

46. Dhaliwal K, Scholefield E, Ferenbach D, et al. Monocytes control secondphase neutrophil emigration in established lipopolysaccharide-induced murine lung injury. Am J Respir Crit Care Med. 2012;186(6):514-24.

47. Gandhirajan RK, Meng S, Chandramoorthy HC, et al. Blockade of NOX2 and STIM1 signaling limits lipopolysaccharide-induced vascular inflammation. J Clin Invest. 2013;123(2):887-902.

48. Green LR, Monk PN, Partridge LJ, Morris P, Gorringe AR, Read RC. Cooperative role for tetraspanins in adhesin-mediated attachment of bacterial species to human epithelial cells. Infect Immun. 2011;79(6):2241-9.

49. Kudoh I, Wiener-Kronish JP, Hashimoto S, Pittet JF, Frank D. Exoproduct secretions of Pseudomonas aeruginosa strains influence severity of alveolar epithelial injury. Am J Physiol. 1994;267(5 Pt 1):L551-6.

50. Roy-Burman A, Savel RH, Racine S, et al. Type III protein secretion is associated with death in lower respiratory and systemic Pseudomonas aeruginosa infections. J Infect Dis. 2001;183(12):1767-74.

51. Wiener-Kronish JP, Albertine KH, Matthay MA. Differential responses of the endothelial and epithelial barriers of the lung in sheep to Escherichia coli endotoxin. J Clin Invest. 1991;88(3):864-75. 
52. Zhou F, Ciric B, Li H, et al. IL-10 deficiency blocks the ability of LPS to regulate expression of tolerance-related molecules on dendritic cells. Eur J Immunol. 2012;42(6):1449-58.

\section{Publisher's Note}

Springer Nature remains neutral with regard to jurisdictional claims in published maps and institutional affiliations.
Ready to submit your research? Choose BMC and benefit from:

- fast, convenient online submission

- thorough peer review by experienced researchers in your field

- rapid publication on acceptance

- support for research data, including large and complex data types

- gold Open Access which fosters wider collaboration and increased citations

- maximum visibility for your research: over $100 \mathrm{M}$ website views per year

At BMC, research is always in progress.

Learn more biomedcentral.com/submissions 